\title{
Oxygen Transfer in Fermentation Systems-I. Use of Gluconic Acid Fermentation for Determination of Instantaneous Oxygen Transfer Rates*
}

\author{
George T. Tsao and Lloyd L. Kempe, Department of Chemical \\ Engineering, The University of Michigan, Ann Arbor, Michigan
}

Summary. Oxygen transfer has been studied in the Pseudomonas ovalis fermentation that quantitatively converts glucose into gluconic acid. The rate of oxygen uptake by this system was correlated with aeration rates and agitator speeds over wide ranges of these variables, by the introduction of a liquid expansion term. The technique described provides a biological method for studying oxygen transfer in the $P$. ovalis system; its general principles can be applied to other fermentations.

\section{Introduction}

The oxygenating capacity of fermentors has been evaluated by sulphite oxidation and polarographic methods. ${ }^{1-5,7,9,10,12,14-19,21}$ Both techniques are only partially successful for this purpose; the first ignores the presence of micro-organisms, ${ }^{1-5}, 7,10,12,15-19$ the second requires artificial conditions such as removal of oxygen or poisoning of the cells.1, 9, 14, 21

This paper presents a new biological technique for the continuous and instantaneous measurement of oxygen transfer in systems containing microbial cells. The technique is based upon discovering a metabolic product that has a constant and quantitative relation to the oxygen consumed and which can be conveniently determined. Once this has been done, the rate of oxygen transfer is measured by observing the rate of formation of the selected product.

\footnotetext{
* Presented before the 136th National Meeting of the American Chemical Society, Atlantic City, N.J., September 1959. 
The method will be illustrated by its application in the Pseudomonas ovalis fermentation that quantitatively converts glucose into gluconic acid and from which a correlation between oxygen uptake, power input, air flow, and liquid expansion were developed.

\section{Development of the Empirical Equations}

In submerged, aerobic fermentation systems, oxygen transfer is controlled by its movement from the air bubbles to the fluid, by diffusion in the fluid, or by transfer across the liquid-cell boundary. In our gluconic acid fermentation broths, the second step is assumed to be sufficiently rapid so that it does not become rate limiting. Oxygen entering the microbial cells is used in biochemical reactions; when these reactions are not limiting, the overall rate of oxygen utilization by the fermentation system is controlled either by the rate of oxygen transfer across the gasliquid interface or across the liquid-cell boundary.

A transfer equation may be written in the following form:

$$
\frac{d c}{d t}=K A \Delta f
$$

When this equation is applied to a gas-liquid interface, oxygen transfer can be expressed as:

$$
\frac{d c}{d t}=K A\left(f_{g}-f_{l}\right)
$$

If the rate limiting step in an overall process occurs at the gasliquid interface, then $f_{l}$ will be negligible compared with $f_{g}$ and equation (2) can be approximated by equation (3) or equation (3a).

$$
\begin{aligned}
& \frac{d c}{d t}=K A f_{g} \\
& \frac{d c}{d t}=K A y_{g}
\end{aligned}
$$

With ordinary air, where the partial pressure of oxygen is substantially constant, the oxygen transfer rate is approximately 
proportional to the product of a transfer coefficient and the transferring area at the gas-liquid interface, i.e.

$$
\frac{d c}{d t} \propto K A
$$

Similarly, equations $(5,6,6 a$, and 7$)$ can be written for those systems where the overall oxygen transfer rate is controlled by the resistance at the liquid-cell boundary. In this case, it is assumed that $f_{s}$ is negligible and that $x_{l}$ is essentially constant and approximately equal to the oxygen solubility in the liquid.

$$
\begin{aligned}
& \frac{d c}{d t}=K^{\prime} A^{\prime}\left(f_{l}-f_{s}\right) \\
& \frac{d c}{d t}=K^{\prime} A^{\prime} f_{l} \\
& \frac{d c}{d t}=K^{\prime} A^{\prime} x_{l} \\
& \frac{d c}{d t} \propto K^{\prime} A^{\prime}
\end{aligned}
$$

In submerged fermentation systems, both the gas-liquid and liquid-cell boundaries are involved in oxygen transfer. For either boundary, if $K A$ is considered to be a function of the factors in equation (8),

$$
K A=F(P, G, \rho, \mu, d, L, \sigma, l)
$$

A relation can be obtained by aid of dimensional analysis :

$$
K A=k_{1} \rho G\left(\frac{L}{d}\right)^{k_{2}}\left(\frac{G \rho d^{2}}{\mu}\right)^{k_{3}}\left(\frac{P d}{G_{\sigma}}\right)^{k_{4}}\left(\frac{\sigma}{d^{3} G^{2} \rho}\right)^{k_{5}}\left(\frac{1}{L}\right)^{k_{6}}
$$

In the present experiments, conditions were arranged so that the terms, $L, d, \mu, \rho$, and $\sigma$, were constant in a given series of runs. Equation (9) therefore reduced to

where

$$
K A=k_{7} P^{k_{8} G^{k} k_{9} E^{k_{10}}}
$$

$$
E=\frac{1}{L} \times 100
$$


When the agitator speed was included in place of power input, as shown in equation (12),

$$
K A=F(N, G, \rho, \mu, d, L, \sigma, l)
$$

then a similar equation was derived which utilized $N$ in place of $P$. This yielded:

$$
K A=k_{11} N k_{12} G^{k_{13}} E^{k_{14}}
$$

The results obtained were correlated with equations (10) and (13). The coefficients and the exponential constants were determined by graphical trial and error analyses and the method of least squares. It should be noted that the derived equations are empirical in nature.

\section{Materials and Methods}

Pseudomonas ovalis NRRL-B-8 oxidizes glucose into gluconic acid as a terminal metabolic product. The reaction can be expressed in the following form:

$$
\mathrm{C}_{6} \mathrm{H}_{12} \mathrm{O}_{6}+\frac{1}{2} \mathrm{O}_{2} \longrightarrow \mathrm{CH}_{2} \mathrm{OH}(\mathrm{CHOH})_{4} \mathrm{COOH}
$$

Lockwood, Tabenkin and Ward ${ }^{11}$ reported that glucose present in the fresh medium was either converted into gluconic acid by the organism or it remained as unused glucose. This was confirmed by analysis of fermented media during the present study: results from 24-h culture media showed that 99.0 per cent of the glucose fermented was converted into gluconic acid.

A continuous recording technique was introduced by Finn ${ }^{6}$ and developed by Gillies, ${ }^{8}$ and West ${ }^{20}$ to measure the instantaneous rate of acid formation in the lactic acid fermentation. The same technique was used in the present work to measure the rate of gluconic acid formation by resting cells of Pseudomonas ovalis NRRL-B-8. The rate of oxygen transfer into the fermenting broth was expressed in terms of the rate of acid formation.

(a) Fermentor. A 5-1. cylindrical glass fermentor was used in the present oxygen transfer study. This fermentor was 6 in. in diameter and $12 \mathrm{in.} \mathrm{high.} \mathrm{Four} \mathrm{stainless-steel} \mathrm{baffle} \mathrm{plates,} \mathrm{each}$ $11.5 \times 0.625$ in., were fixed to the head plate. They were tied together by a stainless-steel ring at the bottom. The baffle 
plates were placed at right angles with their surfaces perpendicular to the fermentor walls and their lower ends 0.5 in. above the bottom of the vessel. Through the head plate an agitator shaft was centrally mounted, on which an impeller was fixed at 2.5 in. above the bottom of the fermentor. The impeller was made of four $0.625 \times 0.625$ in. stainless-steel blades, set $90^{\circ}$ apart with their flat surfaces perpendicular to the bottom of the vessel. An air pipe passed through the head plate; at its tip, a single hole sparger was attached with the aperture facing upward, $0.6 \mathrm{in}$. below the impeller.

(b) $p H$ Controlling System. The calomel and glass electrodes were attached to the baffle plates of the fermentor so that their tips dipped into the broths. The electrodes were connected to a Bristol pH-controller. During an experiment, the gluconic acid produced by the Pseudomonas ovalis cells lowered the $\mathrm{pH}$ of the liquid. Once the $\mathrm{pH}$ reached a desired value, the controller started a pump that added a sodium hydroxide solution to the mash. The rate at which sodium hydroxide was added was proportional to the rate of gluconic acid formation. A diagram of the equipment used is shown in Fig. 1.

The sodium hydroxide solution was contained in a one-litre graduate, $t$, which was connected to the fermentor, $m$, through the pump, p. A float, s, rested on the surface of the sodium hydroxide solution. This float was fabricated from a glass bulb fastened to a light wooden stick to which an ink-pointer, w, was attached. The tip of the pen pressed against the surface of the drum, r, which was driven by a clock motor, $u$, at a speed of 24 or $12 \mathrm{rev} / \mathrm{h}$, as desired. During an experiment, the ink-pointer traced a curve on a sheet of paper fastened to the surface of the drum. The vertical coordinate indicated the volume of the sodium hydroxide solution in the reservoir, $t$; the horizontal coordinate indicated the time elapsed. The rate at which sodium hydroxide was pumped into the fermentor at any instant was obtained by graphical differentiation of the curve using a platen that was specially designed for this purpose.

(c) Accessories. Air was obtained from the laboratory compressed air line; the air flow rate was measured with a rotometer. A stroboscope or a tachometer was used to measure the agitator speed. The level of the liquid in the fermentor was read against 
a scale marked on the outside of the glass vessel and power input to the system through the agitator was measured with a springtype dynamometer and a stroboscope.

(d) Preparation of Cultures and Resting Cells of Pseudomonas ovalis. The culture of Pseudomonas ovalis NRRL-B-8 used in this study was obtained from the Northern Utilization Research

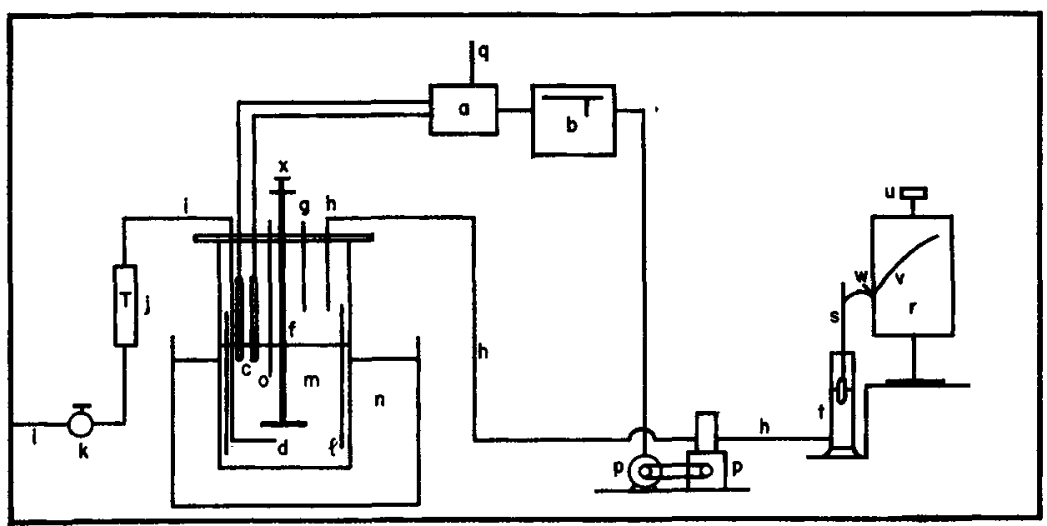

Fig. 1. Equipment used in oxygen transfer studies with Pseudomonas ovalis
a : pH meter
$\mathrm{b}: \mathrm{pH}$ controller and recorder
c: Electrodes
d: Air sparger
e: Impeller
f: Agitator shaft
: Sampling tube
$\mathrm{h}$ : $\mathrm{NaOH}$ feed line
i: Air line
j: Flow meter
k: Valve
I: Baffle plates
m : Fermentor
$\mathrm{n}$ : Constant temperature water bath
$o$ : Thermometer holder
q: Power line
r: Kymograph drum
s: Float
$\mathrm{t}$ : $\mathrm{NaOH}$ solution reservoir
u : Clock motor
v: Curve drawn
w : Ink-pointer
$\mathrm{p}$ : Sigma pump and motor $\mathrm{x}$ : Spring dynamometer

and Development Division of the United States Department of Agriculture at Peoria, Illinois. The medium used for culturing this organism was of the following composition :

$\begin{array}{ll}\text { glucose } & 50 \mathrm{~g} \\ \mathrm{KH}_{2} \mathrm{PO}_{4} & 0.6 \mathrm{~g} \\ \mathrm{MgSO}_{4} & 0.25 \mathrm{~g} \\ \text { urea } & 2.0 \mathrm{~g} \\ \text { yeast extract } & 5.0 \mathrm{~g} \\ \text { distilled water } & 1.0 \mathrm{l} .\end{array}$

When a solid medium was required, $20 \mathrm{~g}$ of agar was also added. In preparation for an experiment, a slant culture was first 
inoculated and incubated for $24 \mathrm{~h}$ at $30^{\circ} \mathrm{C}$. These cells were washed into one litre of fresh liquid medium in a $1 \cdot 5-1$. Florence flask. The liquid media used in the culture tubes and in the 1.5-1. flasks were of the composition given above.

The inoculated medium in the $1 \cdot 5$-l. flask was next incubated at $30^{\circ} \mathrm{C}$ on a rotary shaker that rotated the flask at $200 \mathrm{rev} / \mathrm{min}$ in a circle of one inch diameter. After $24 \mathrm{~h}$, the cells were centrifuged from the broth and resuspended in 21 . of a buffered glucose solution of the following composition :

$\begin{array}{lc}\text { glucose } & 50 \mathrm{~g} \\ \mathrm{KH}_{2} \mathrm{PO}_{4} & 1.2 \mathrm{~g} \\ \text { distilled water } & 2.0 \mathrm{l} .\end{array}$

No nitrogen was present in the solution. This resting cell suspension was used for the respiration study carried out in the 5-1. fermentor.

(e) Experimental Procedure. Two series of experiments were conducted with resting cells of Pseudomonas ovalis; in the first, the combined effect of power input, agitation and air flow on the rate of oxygen transfer was studied; in the second, the effect of cell concentration on the rate of gluconic acid production was investigated.

In the first series of experiments, $880 \mathrm{ml}$ of a 24-h Pseudomonas ovalis culture were centrifuged and resuspended to make approximately $2 \mathrm{l}$. of a cell suspension as previously described. The number of cells in the suspension was adjusted turbidemetrically to contain $1.76 \times 10^{10}$ cells per $\mathrm{ml}$.

The cell suspension was poured into the 5-1. fermentor, four drops of an antifoaming agent, Dow polyglycol P-2000, were added, the headplate was mounted, the agitator and air flow were started, and, finally, the $\mathrm{pH}$ controller was set at a value of $5 \cdot 5$. The changing level of the alkali solution in the graduate was automatically recorded on the drum, $r$, shown in Fig. 1. This drum turned once in $24 \mathrm{~h}$.

In each run, the acid production rate started at a low value but increased quickly until after 30 to 60 min a steady rate of acid production was established. This was indicated by a constant slope of the trace drawn on the drum, r. The experiment was then considered to be under way. It was continued for one to two hours. This time was needed to allow the line drawn on the drum to 
become sufficiently extended for its slope to be accurately measured.

One level of agitator speed and one air flow rate were studied at different agitator speeds and air flow rates using the methods described. The results obtained are given in Table I. Equa-

Table I. Effects of power input, agitation and air flow on the rate of gluconic acid production by Pseudomonas ovalis NRRL-B-8

\begin{tabular}{|c|c|c|c|c|}
\hline $\begin{array}{l}\text { Agitator } \\
\text { speed, } \\
N \\
\mathrm{rev} / \mathrm{min}\end{array}$ & $\begin{array}{c}\text { Air flow } \\
\text { rate, } \\
G \\
\operatorname{vrm}\end{array}$ & $\begin{array}{c}\text { Power } \\
\text { input, } \\
P \\
\text { h.p./l.h } \\
\times 10^{-3}\end{array}$ & $\begin{array}{c}\text { Rate of acid } \\
\text { production, } \\
\text { mole/l. h } \\
\times 10^{-3}\end{array}$ & $\begin{array}{c}\text { Liquid volume } \\
\text { expansion } \\
E, \\
\text { per cent } \\
\text { by vol }\end{array}$ \\
\hline 470 & $1 \cdot 16$ & $10 \cdot 7$ & $3 \cdot 75$ & $9 \cdot 3$ \\
\hline 370 & $1 \cdot 16$ & $7 \cdot 4$ & $3 \cdot 75$ & $4 \cdot 9$ \\
\hline 470 & 0.31 & $12 \cdot 3$ & $4 \cdot 0$ & $5 \cdot 8$ \\
\hline 470 & $1 \cdot 81$ & $10 \cdot 5$ & $4 \cdot 0$ & $9 \cdot 5$ \\
\hline 470 & 0.73 & 11.8 & $4 \cdot 75$ & $4 \cdot 9$ \\
\hline 100 & $1 \cdot 16$ & $2 \cdot 2$ & $2 \cdot 0$ & $1 \cdot 5$ \\
\hline 270 & $1 \cdot 16$ & $4 \cdot 4$ & $3 \cdot 5$ & $2 \cdot 6$ \\
\hline 370 & $1 \cdot 16$ & $7 \cdot 4$ & $4 \cdot 24$ & $3 \cdot 5$ \\
\hline 270 & $1 \cdot 81$ & $4 \cdot 3$ & $3 \cdot 75$ & 3.0 \\
\hline 270 & 0.31 & $4 \cdot 6$ & $3 \cdot 0$ & $2 \cdot 5$ \\
\hline 100 & $1 \cdot 81$ & $2 \cdot 2$ & 1.75 & 1.5 \\
\hline 100 & 0.73 & $2 \cdot 2$ & $1 \cdot 62$ & $1 \cdot 3$ \\
\hline 270 & $1 \cdot 81$ & $4 \cdot 4$ & $3 \cdot 0$ & $4 \cdot 8$ \\
\hline 270 & 0.73 & $4 \cdot 5$ & $3 \cdot 12$ & $2 \cdot 4$ \\
\hline
\end{tabular}

tion (10), developed by dimensional analysis, suggested that a linear correlation should result when the proper groups of variables were plotted on logarithmic coordinates, so this procedure was followed.

A graphical trial and error method was used to determine the exponential constants; the values of $k_{8}, k_{9}, k_{10}$, thus determined, were $0.8,0.2$ and -0.5 , respectively. This is shown in equation (14):

$$
K A=0.2 P^{0.8} G^{0.2} E^{-0.5} \text { moles } \mathrm{O}_{2} / 1 . \mathrm{h}
$$

The coefficients were determined by the method of least squares. The overall correlation showing the effect of power input on the system is graphically presented in Fig. 2, while that for equation (14) is given in Fig. 3. 


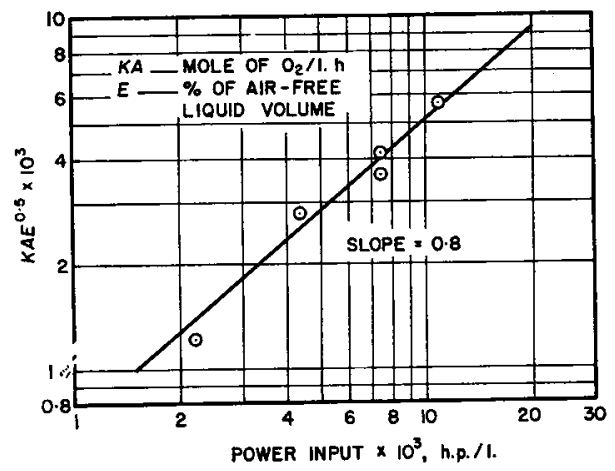

Fig. 2. Effect of power input on the rate of oxygen transfer in the Pseudomonas ovalis system

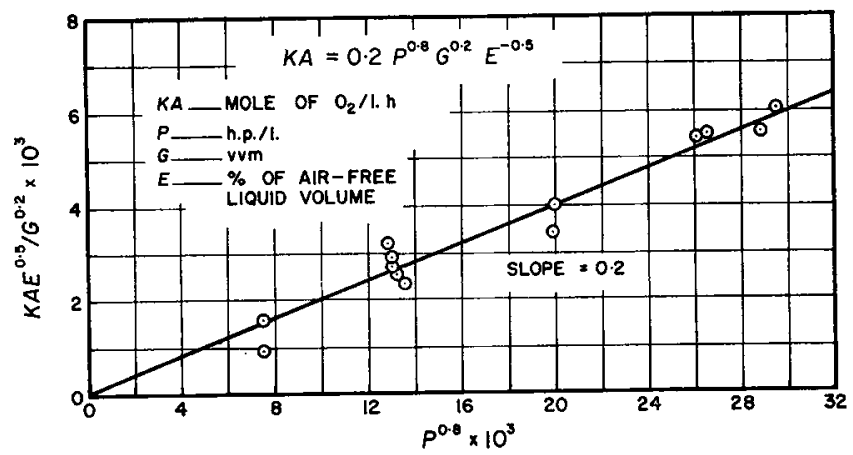

Fig. 3. Effects of power input and air flow on the rate of oxygen transfer in the Pseudomonas ovalis system

When the factor $N$ was substituted for power input, equation (15) was obtained:

$$
K A=3.43 \times 10^{-6} N^{1 \cdot 2} G^{0.2} E^{-0.5} \text { moles } \mathrm{O}_{2} / 1 . \mathrm{h}
$$

The corresponding plot is shown in Fig. 4.

The effect of cell concentration on the rate of oxygen transfer was also investigated by the experimental methods previously described, using two levels of agitator speed as well as two air flow rates. The results of the experiments are shown in Fig. 5, where it is seen that a linear relation exists between the cell concentration and the rate of acid production. 


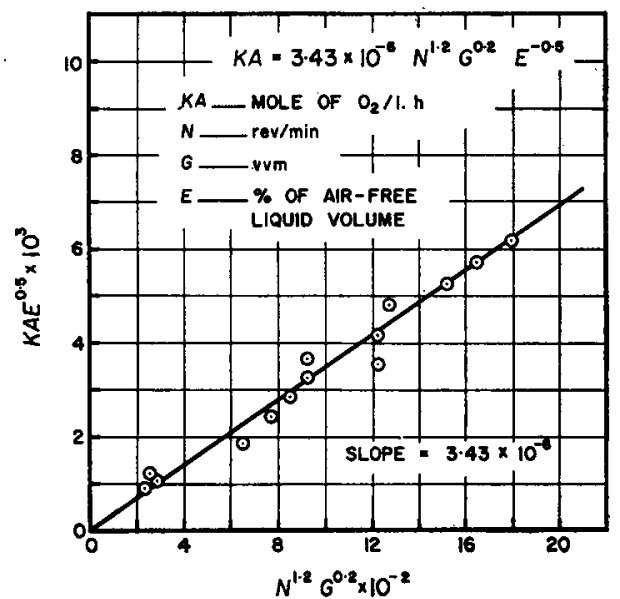

Fig. 4. Effects of agitation and air flow on the rate of oxygen transfer in the Pseudomonas ovalis system

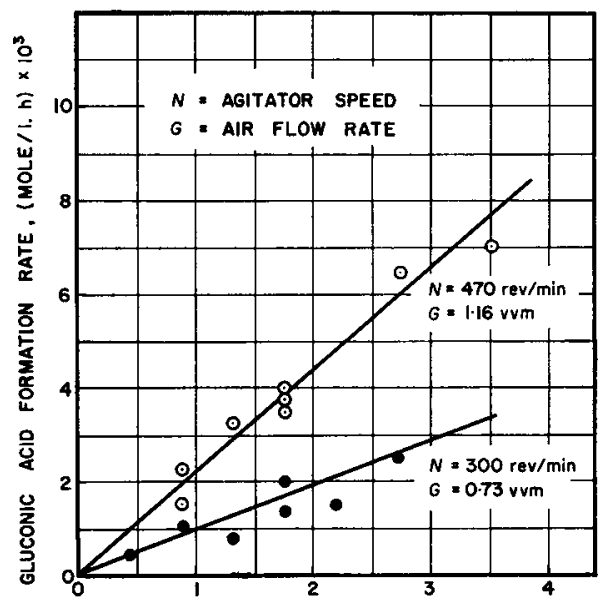

CELL CONCENTRATION, (CELLS $/ \mathrm{m} 1) \times 10^{-10}$

Fig. 5. Effect of cell concentration on the rate of gluconic acid formation in the Pseudomonas ovalis system

\section{Discussion}

The Pseudomonas ovalis fermentation of glucose to gluconic acid proposed in this paper is a biological method for determining 
the rate of oxygen uptake. The method is based upon the assumption that a definite ratio exists between the amount of oxygen consumed and of gluconic acid produced. Because microbial cells were actually involved in this oxygen uptake measurement, the method provides a biological way of evaluating the oxygen transfer performance of fermentors.

In actual fermentations, three phases are involved: gas, liquid and solid. In such systems, the overall oxygen transfer rate may be controlled by either the gas-liquid or the liquid-cell interfaces. In either case, the rate of oxygen uptake is proportional to the product of a transfer coefficient and a transferring area, as shown in equations (4) and (7). When the gas-liquid interface is limiting, the transfer coefficient and the transferring area are those associated with the gas-liquid interface; in the other cases, they refer to the transfer coefficient and the transferring area at the liquid-cell boundary. If the overall oxygen uptake rate is limited by the liquid-cell boundary, and if the bacterial cells involved are of similar size and shape, the rate of oxygen uptake, as shown in equation (7), should be proportional to the cell concentration of the system. This linear relationship is observed in Fig. 5. The derivation of equation (7) was based upon two assumptions; namely, that $f_{s}$ in equation (5) is negligible and that $f_{l}$ is approximately constant and close to the oxygen transfer potential of a broth saturated with oxygen. These assumptions might profitably be considered in connection with the runs for which data are presented in the table.

At present, there is no adequate method for measuring $f_{s}$, the oxygen transfer potential of the bacterial cells. Probably oxygen is instantaneously fixed and quickly used by the enzyme systems; hence, the resistance to further oxygen transfer as well as the value of $f_{s}$ should be negligible.

The second condition, namely that of a high and essentially constant $f_{l}$, probably existed in these runs. This presumption proceeds from the following interpretation of the results.

First of all, if the liquid-cell interface is controlling, the $f_{l}$ will almost certainly be high.

Secondly, using sulphite oxidation data taken in the same fermentor with the same agitator speeds and air flows, the oxygen supply rate was calculated to be in the range of 0.01 moles $/ 1 . h$. 
Based upon data in the table, the oxygen requirements for glucose oxidation were approximately one-tenth of this.

Such a difference between the rate of oxygen supply and demand should have produced a high $f_{l}$ value.

Finally, the data in Fig. 5 show a five-fold rise in the oxygen uptake rate caused by increasing the cell concentration in the suspension; a further increase could be expected from extrapolation of the curves.

This would suggest that eventually, as the cell concentration was increased, the correspondingly higher oxygen demands could cause the gas-liquid interface to become controlling. However, in our runs, which were conducted with low cell concentrations, the effect of resistance at the gas-liquid interface must have been small. Since both the agitator speed and the air flow were constant in these runs, overcoming a resistance at the gas-liquid interface could only have resulted from an increase in the potential difference, as shown by equation (2). Because $f_{g}$ is constant, $f_{l}$ is the only term that could have varied; so, in order to produce a five-fold increase in the oxygen transfer across the gas-liquid interface, the value of $f_{l}$ in the experiments reported in the table would have needed to be at least four-fifths of the saturation level at low cell concentrations.

Based upon the same reasoning, the variability in $f_{l}$ must have been confined to a maximum of one-fifth of the saturation value when cell concentration was low.

These considerations suggest that a high and relatively constant dissolved oxygen concentration existed in the broth during runs discussed in the table; they also help to substantiate a contention that the observed effects of agitation and power changes on oxygen uptake rates resulted from the alteration of transfer resistances at the liquid-cell interface.

From preliminary experiments, it was found that the rate at which gluconic acid was formed was not materially affected by temperature changes. The effects of physical factors such as air flow rate, power input, and agitator speed on the rate of acid production were shown in equations (14) and (15). From these data it was apparent that in these instances, oxygen transfer was controlled by the physical process of mass transfer. This follows because chemical reactions are affected by temperature changes 
but do not show appreciable response to variation of physical factors such as agitation.

From other preliminary experiments, it was found that changes in the concentrations of glucose, phosphate and gluconic acid in the liquid had no effect upon the rate of acid formation. This indicates that oxygen transfer was the rate controlling factor.

These considerations, together with the linear relationship found between cell concentration and oxygen transfer rates, indicate that the bacterial surface area can be directly associated with the rate controlling mechanism in the oxygen transfer process of the Pseudomonas fermentation and suggest that, in these studies, the transferring step across the liquid-cell interface did control the overall utilization of oxygen.

Acknowledgment. The financial support of this work through a grant from the National Science Foundation is gratefully acknowledged.

\section{Nomenclature}

A Transferring area

$A^{\prime} \quad$ Transferring area where liquid-cell-wall interface is rate controlling

d Impeller diameter

$E \quad$ Liquid volume expansion factor defined by equation (11)

$f_{g} \quad$ Oxygen transfer potential of gas phase

$f_{l} \quad$ Oxygen transfer potential of liquid phase

$f_{s} \quad$ Oxygen transfer potential of solid phase

$G \quad$ Air flow rate

$k_{1}, k_{2}, k_{3}$, etc. Constants

$K$

Transfer coefficient

$K^{\prime}$

Transfer coefficient where liquid-cell-wall interface is rate controlling

$l$

$L$

Total liquid volume increase due to air held-up

Total volume of the air-free liquid

$N$

Agitator speed

$P$

Power input per unit volume of liquid

$x_{l}$

Mass fraction of oxygen in liquid phase

$y_{g}$

Mass fraction of oxygen in gas phase 
$\begin{array}{ll}\sigma & \text { Surface tension of the liquid } \\ \rho & \text { Density of the liquid } \\ \mu & \text { Viscosity of the liquid } \\ d c & \text { Overall rate of oxygen uptake } \\ \overline{d t} & \text { Oxygen transfer potential difference }\end{array}$

\section{References}

1 Bartholomew, W. H., Karow, E. O., Sfat, M. R. and Wilhelm, R. H. Industr. Engng Chem. (Industr.), 42, 1601 (1950)

2 Brierley, M. R. and Steel, R. Appl. Microbiol., 7, 57 (1959)

3 Carpani, R. E. and Roxburgh, J. M. Canad. J. chem. Engng, 36, 73 (1958)

4 Cooper, C. M., Fernstrom, G. A. and Miller, S. A. Industr. Engng Chem. (Industr.), 36, 504 (1944)

5 Elsworth, R., Williams, V. and Harris-Smith, R. J. appl. Chem., 7, 261 (1957)

${ }^{6}$ Finn, R. K., Halvorson, H. O. and Piret, E. L. Industr. Engng Chem. (Indust.), 42, 1857 (1950)

7 Friedman, A. M. and Lightfoot, E. N., Jr. Industr. Engng Chem. (Industr.), 49, 1227 (1957)

8 Gillies, R. A. Ph.D. Thesis, University of Michigan, Ann Arbor, Michigan (1955)

9 Hixon, A. W. and Gaden, E. L., Jr. Industr. Engng Chem. (Industr.), 42, $1792(1950)$

10 Karow, E. O., Bartholomew, W. H. and Sfat, M. R. J. Agr. Food Chem., 42, $1792(1950)$

11 Lockwood, L. B., Tabenkin, B. and Ward, G. E. J. Bact., 42, 51 (1941)

12 Maxon, W. D. and Johnson, M. J. Industr. Engng Chem. (Industr.), 45, 2554 (1953)

13 Phillips, D. H, and Johnson, M. J. Industr. Engng Chem. (Industr.), 51,83 (1959)

14 Rolinson, G. N., Jr. J. gen. Microbiol., 6, 336 (1952)

15 Roxburgh, J. M., Spencer, J. F. T. and Sallans, H. R. Appl. Microbiol. 2, 1121 (1954)

16 Schultz, J. and Gaden, E. L., Jr. Industr. Engng Chem. (Industr.), 48 2209 (1956)

17 Solomons, G. L. J. Appl. Chem., 8, 445 (1958)

18 Solomons, G. L. and Perkin, M. P. J. Appl. Chem., 8, 251 (1958)

19 Steel, R. and Brierley, M. R. Appl. Microbiol., 7, 51 (1959)

20 West, R. E. Ph.D. Thesis, University of Michigan, Ann Arbor, Michigan (1957)

21 Wise, W. S. J. gen. Microbiol., 5, 167 (1951) 